\title{
Biochemical and Chemical Lipid Profile and Blood Pressure Assessment in Arterial Hypertension with Chronic Kidney Disease
}

\author{
TEIM BAAJ ${ }^{1}$, AHMED ABU-AWWAD ${ }^{1 *}$, MIRCEA BOTOCA ${ }^{1}$, \\ OCTAVIAN MARIUS CRETU ${ }^{1}$, ELENA ARDELEANU ${ }^{1}$, IOAN MUSTA ${ }^{1}$, \\ IOAN TILEA ${ }^{2}$, SHAMSA BAAJ ${ }^{3}$, ANDREI PAUNESCU ${ }^{1}$, ANDREI RUSMIR ${ }^{1}$, \\ SILVIU LATCU ${ }^{1}$, SEBASTIAN PLESA ${ }^{1}$, ADINA ELENA PROTESI ${ }^{1}$, ALIN CUMPANAS ${ }^{1}$, \\ LAURENTIU SIMA ${ }^{1}$ \\ ${ }^{1}$ Victor Babes University of Medicine and Pharmacy, 2 Eftimie Murgu Sq., 300041, Timisoara, Romania \\ ${ }^{2}$ University of Medicine and Pharmacy Tirgu Mures, 38 Gh. Marinescu Str., 540134, Tirgu Mures, Romania \\ ${ }^{3}$ Harvard Medical School, 55 Fruit Str., GRB 444 Boston, MA 02114, SUA
}

\begin{abstract}
Accelerated atherosclerosis and cardiovascular diseases are frequent complications in hypertensive patients with chronic kidney disease (CKD), being mainly driven by cardiovascular risk factors as lipid disorders and an unfavorable blood pressure profile. The objectives of the study were to evaluate the lipid profile and to assess the characteristics of blood pressure (BP) in patients with primary arterial hypertension associating chronic kidney disease (CKD) in a primary care population in Timis County, Romania. Lipid disorders were highly prevalent in hypertensive patients with CKD, consisting in hyper LDL-cholesterolemia in 50.3\%, hypertriglyceridemia in 52\%, low HDL-cholesterol levels in 35.8\%. More than 2 lipid abnormalities were present in $68.8 \%$ of CKD hypertensive. CKD hypertensive patients, compared with those without CKD, presented a BP profile with higher systolic and diastolic office BP. On ambulatory blood pressure monitoring they also registred higher systolic and diastolic BP, the systolic BP (SBP), both for $24 \mathrm{~h}$ SBP, day-time and night-time SBP being statistically significant higher than in hypertensive patients without $C K D$. The circadian $24 h B P$ profile demonstrated in the CKD hypertensive population an unfavourable nocturnal profile in 67\%, consisting of a high prevalence of the non-dipping profile and of nocturnal riser pattern.
\end{abstract}

Keywords: chemical lipid profile, biochemical lipid profile, hypertension, chronic kidney disease, lipid disorders

\section{Introduction}

The prevalence of CKD (Chronic Kidney Disease) mediated by hypertension demonstrates a rising tendency worldwide and in Romania. As many studies have demonstrated, hypertension associating CKD carries out major risks for the development of accelerated atherosclerosis, cardiovascular, cerebral and renal complications and of a worse prognosis. Studies have demonstrated that high levels of blood pressure (BP) are positively and significantly related to the decline of the kidney function among the hypertensive population. Blood pressure is a highly dynamic parameter, showing circadian variations determined by physiological, neuroendocrine and environmental factors [1]. In the absence of complete and careful assessment of the entire $24 \mathrm{~h}$, daytime and night-time BP pattern with ambulatory blood pressure monitoring (ABPM), the diagnosis of hypertension in CKD patients can be inaccurate and sometime missed.

In Romanian primary care units, the diagnosis of hypertension is mainly based on office BP measurements, completed by home blood pressure monitoring and only rarely evaluated with ABPM. During the last years, ABPM has become increasingly more used in primary care units in Timis County, as studies have demonstrated that it provides more reliable and reproducible information about $\mathrm{BP}$, being more closely related to target organ damage, cardiovascular (CV) events and prognosis.

*email:ahm.abuawwad@gmail.com 
Alterations of the 24-h BP profile, such as a blunted sleep-time decline, increased night-time BP, short and long-time high BP variability or postprandial hypotension, reflect an altered cardiovascular $\mathrm{BP}$ regulation and predict a high prevalence of hypertension-mediated organ damage and future $\mathrm{CV}$ events [2-3]. In our country, important epidemiological studies regarding prevalence, risk factors and characteristics of essential hypertension in the general population are the SEPHAR I-III Surveys [4-5]. These trials did not include ABPM, so there is a lack of information about the $24 \mathrm{~h}$ BP profile of the Romanian hypertensive population but, based on office measurements, they demonstrated that $44 \%$ of the Romanian adult population presents hypertension, multiple cardiovascular risk factors and $83 \%$ have different forms of dyslipidaemia.

Accelerated atherosclerosis and cardiovascular disease are the main causes of death in patients with chronic kidney disease (CKD). Atherosclerosis, cardiovascular diseases and other complications of CKD are also driven by lipid disorders, oxidative stress and inflammation [6]. Patients with mild to moderate CKD exhibit frequently hypercholesterolemia, elevated low-density lipoprotein (LDL), elevated serum triglycerides and very low-density lipoprotein (VLDL) levels. An impaired clearance of VLDL, chylomicrons and their atherogenic remnants is noticed in the CKD hypertensive population [7-8]. The reduction in serum apoA-1 and that of high-density lipoprotein (HDL) cholesterol concentration, impaired HDL maturation and defective HDL antioxidant, anti-inflammatory and reverse cholesterol transport capacities met in CKD patients have an important role in accelerating atherosclerosis [9]. We noticed that there is a lack of study data regarding the BP and lipid profile of hypertensive patients with CKD in the western part of Romania.

The objectives of the present study were to assess the lipid profile and the $24 \mathrm{~h}$ BP profile of a hypertensive population associating CKD, evaluated in primary care conditions in Timis County, Romania.

\section{Materials and methods}

This is an observational cross-sectional study of a database of hypertensive patients from fourteen primary care offices of Timis County, Romania, done between February 2017 and December 2019. The selection of the subjects was made by the general practitioners (GPs) who participated in this study. Inclusion criteria were adults over 18 years, diagnosed with recent or old essential arterial hypertension. Exclusion criteria were secondary hypertension, febrile illness, mental illness, gestation and acute myocardial infarction. A number of 1214 hypertensive patients were evaluated during this period in primary care offices of Timis County, who were included in this study. A part of the participants did not complete the study, in the final analysis being included 984 (81.06\%) hypertensive patients, who had completed data. Of these, 131 cases (13.32\%) were diagnosed with CKD mediated by hypertension. In conformity with the World Medical Association Declaration of Helsinki, at the beginning of the study all participants signed a written informed consent. Blood pressure measurements were done during the first visit according to the ESC/ESH Hypertension Guidelines [1]. Validated and calibrated BP measuring devices (OMRON HEM 7251G) were used for office BP measurement and BTL 04 monitors for ABPM. Office readings were obtained by applying careful and standardized measurement techniques, being performed with the patient in a seated position, after at least $5 \mathrm{~min}$ of rest and more than $30 \mathrm{~min}$ apart from smoking or drinking coffee, with the back supported, legs uncrossed, with the cuff positioned at the heart level and adapted to the arm circumference. Two BP measurements were taken spaced 2 min apart and considered the average, if appropriate. If BP values were quite different, repeated measurements were done. The second visit of the study participants at the office took place two weeks apart from the first visit, when BP measurements were repeted and ABPM, laboratory investigations and referrals to specialists were performed.

The laboratory analyses included total cholesterol (TC), low density lipoprotein cholesterol (LDLc), high density lipoprotein cholesterol (HDL-c), triglycerides (TG), fasting plasma glucose (FPG), HbA1c, uric acid, creatinine, estimated glomerular filtration rate (eGFR). The laboratory tests were 
performed in conformity with the standardized procedures by the Synevo Laboratories. The diagnosis of dyslipidaemia was based on the following profile (or on treatment): total cholesterol $>200 \mathrm{mg} / \mathrm{dL}$ or LDL-cholesterol $>115 \mathrm{mg} / \mathrm{dL}$ or HDL-cholesterol $<40 \mathrm{mg} / \mathrm{dL}$ for men, $<46 \mathrm{mg} / \mathrm{dL}$ for women and triglycerides $>150 \mathrm{mg} / \mathrm{dL}$.

The general practitioners conducted personally both office BP measurement and ABPM. Day and night-time periods were defined according to the patients' self-reported data of going to bed and walking up. ABPM was performed on a working day, including BP readings every 20 min during daytime and every 30 min during night-time. In this study, it was accepted by the authors as satisfactory: $24 \mathrm{~h}$ ABPM with $\geq 70 \%$ accurate readings, with minimum 20 measurements during daytime and 7 during night-time. The office BP level used for the definition of HT was $\geq 140 / 90 \mathrm{~mm}$ $\mathrm{Hg}$. On ABPM, the level for the definition of hypertension was: $24-\mathrm{h} \mathrm{BP} \geq 130 / 80 \mathrm{mmHg}$, day-time $\mathrm{BP} \geq 135 / 85 \mathrm{mmHg}$ and/or night-time $\mathrm{BP} \geq 120 / 70 \mathrm{~mm} \mathrm{Hg}$ [6-8]. Sustained HT was established when $\mathrm{BP}$ was over the cut-off values both with office BP measurements and ABPM. Isolated nocturnal hypertension was defined by increased absolute levels of night-time BP $\geq 120 / 70 \mathrm{~mm} \mathrm{Hg}$ and by normal daytime BP $(<135 / 85 \mathrm{~mm} \mathrm{Hg})$. "White-coat" hypertension was defined by elevated OBPM $(\geq$ $140 / 90 \mathrm{mmHg})$ with normal daytime ABPM $(<135 / 85 \mathrm{mmHg})$ [1]. The nocturnal BP pattern included the normal dipping pattern (conferring the best prognosis) or one of the three abnormal BP pattern (non-dipping, riser and extreme dipping). The normal dipping pattern (dipper) was represented by nocturnal BP fall of systolic BP (SBP) $>10 \%$ till to $20 \%$ of the daytime SBP, or the night/day BP ratio $<0.9$ and $>0.8$. For the non-dipping pattern, the nocturnal SBP fall was $<10 \%$ till to $1 \%$ of the daytime SBP, or the night/day ratio $>0.9$. In the riser pattern (having the worst prognosis) night/day $\mathrm{BP}$ ratio was $\geq 1$, with the night-time SBP values being over the daytime SBP [9].

The statistical analyses were performed using SPSS version 12.0. Data were presented as frequencies and percentages for qualitative variables and as mean \pm SD for quantitative variables. Differences between groups were assessed with the Pearson $\chi^{2}$ formula for percentages and the Student $\mathrm{t}$ test for mean values. To determine the correlations between hypertension and other risk factors, the logistic regression analysis was used. The independent variables with $\mathrm{p}<0.05$ were considered as having statistical significance. Odds ratios with $95 \%$ confidence interval (CI) were calculated.

\section{Results and discussions}

The mean age of the hypertensive population with CKD was $62.1 \pm 12.5$ years, being higher than of the total hypertensive population $(49.45 \pm 18.28$ years $), \mathrm{OR}=1.151,95 \% \mathrm{CI}=1.112-1.194, \mathrm{p}<0.001$, demonstrating that older ages are more frequently associated with the decline of the renal function and the development of CKD. Of the 131 hypertensive with CKD, a number of $78(59.5 \%)$ were female and $53(40.5 \%)$ were men, $\mathrm{p}<0.01$, OR $1.5,95 \% \mathrm{CI}=1.39-1.82$. The mean duration of hypertension with CKD was $6.45 \pm 3.47$ years $(95 \% \mathrm{CI}=5.84-7.06)$, compared with a shorter mean HT duration in hypertension without CKD of $6.14 \pm 3.51$ years $(95 \%$ CI $5.54-7.74)$. Significant differences were related to BMI, when comparing hypertension with and without CKD: $30.82 \pm 6.53 \mathrm{~kg} / \mathrm{m}^{2}(95 \%$ CI $29.68-31.96)$ vs. $28.75 \pm 5.45 \mathrm{~kg} / \mathrm{m}^{2}$ (95\% CI $\left.27.81-29.69\right)$. The prevalence of early CKD stages (stage 1 and 2) was $26.76 \%$. Most hypertensive patients with CKD presented a reduced GFR between $59-30 \mathrm{ml} / \mathrm{min} / 173 \mathrm{~m}^{2}$, belonging to stage 3 moderate CKD $(72.52 \%)$. Significant differences between the study groups were noticed regarding a higher prevalence in the CKD group of high glycemia, presence of diabetes mellitus (26.4\% vs $21.85 \%)$, sedentary lifestyle ( $48.8 \%$ vs $45 \%$ ) and family history of premature CVD (31\% vs $19.53 \%)$.

The analysis of office BP measurements revealed differences in hypertension with CKD compared with patients without CKD. In both groups, with and without CKD, office BP measurements were higher than those obtained with ABPM, both for systolic and diastolic BP. In the hypertension group with CKD, the $24 \mathrm{~h}$ systolic BP on ABPM was with nearly $10 \mathrm{~mm} \mathrm{Hg}$ lower than office systolic BP. Systolic BP was greater in CKD measured both with office BP and on ABPM, including all parameters: office SBP $(152.39 \pm 11.41 \mathrm{~mm} \mathrm{Hg}$ vs. $146.72 \pm 10.44 \mathrm{~mm} \mathrm{Hg}), 24 \mathrm{~h} \mathrm{SPB}$, daytime SBP 
and night-time SPB. Office DBP was also more elevated in CKD $(87.39 \pm 6.93 \mathrm{~mm} \mathrm{Hg}$ vs. $86.16 \pm$ $7.93 \mathrm{~mm} \mathrm{Hg}$ in without CKD group), but this difference did not reach statistical significance (Table 1).

Table 1. Office BP measurements and with ABPM in hypertensive patients with and without CKD

\begin{tabular}{|c|c|c|c|c|c|}
\hline \multirow{2}{*}{$\begin{array}{c}\text { BP measurements } \\
\mathrm{mm} \mathrm{Hg}\end{array}$} & \multicolumn{2}{|c|}{ Hypertension with CKD } & \multicolumn{2}{|c|}{ Hypertension without CKD } & \multirow[b]{2}{*}{$p$} \\
\hline & Mean & $95 \% \mathrm{CI}$ & Mean & $95 \% \mathrm{CI}$ & \\
\hline Office SBP & $152.39 \pm 11.41$ & $150.39-154.39$ & $146.72 \pm 10.44$ & $144.92-148.52$ & $<0.05$ \\
\hline Office DBP & $87.39 \pm 6.93$ & $85.17-87.61$ & $86.16 \pm 7.93$ & $85.59-88.33$ & $\mathrm{p}=0.8$ \\
\hline Daytime SBP & $146.53 \pm 11.66$ & $137.48-146.58$ & $139.27 \pm 8.62$ & $132.78-139.76$ & $<0.05$ \\
\hline Daytime DBP & $86.81 \pm 5.76$ & $79.8-86.82$ & $83.24 \pm 6.29$ & $82.16-84.32$ & 0.06 \\
\hline Night-time SBP & $139.65 \pm 12.36$ & $127.48-139.82$ & $125.09 \pm 9.2$ & $119.50-126.68$ & $<0.01$ \\
\hline Night-time DBP & $79.91 \pm 5.81$ & $69.89-80.93$ & $75.49 \pm 6.93$ & $71.29-75.69$ & $<0.05$ \\
\hline $24 \mathrm{~h} \mathrm{SBP}$ & $142.59 \pm 10.83$ & $132.69-142.49$ & $132.68 \pm 7.58$ & $126.37-133.99$ & $<0.05$ \\
\hline $24 \mathrm{~h}$ DBP & $83.90 \pm 5.4$ & $74.95-84.85$ & $77.8 \pm 5.98$ & $76.60-79.00$ & $<0.05$ \\
\hline
\end{tabular}

Abbreviations: SBP, systolic blood pressure; DBP, diastolic blood pressure; CI, confidence interval; ABPM,

mbulatory blood pressure monitoring.

Hypertensive patients with CKD presented higher ambulatory SBP in all ABPM periods (24h, daytime and night-time) compared with hypertensive patients without CKD. The greatest difference regarding ABPM data between the two groups was concerning night-time systolic BP $(139.65 \pm 12.36$ $\mathrm{mm} \mathrm{Hg}$ vs. $125.09 \pm 9.2 \mathrm{~mm} \mathrm{Hg}, \mathrm{p}<0.05)$. Regarding $24 \mathrm{~h} \mathrm{DBP}$, this was with $4 \mathrm{~mm} \mathrm{Hg}$ lower than office DBP in CKD hypertensive patients and with $9 \mathrm{~mm} \mathrm{Hg}$ lower in the hypertensive group without CKD, $\mathrm{p}>0.01$, as presented in Figure 1. ABPM dertected the following hypertension types: sustained hpertension, masked hypertension, nocturnal, "white coat" and resistant hypertension, as presented in Figure 2.
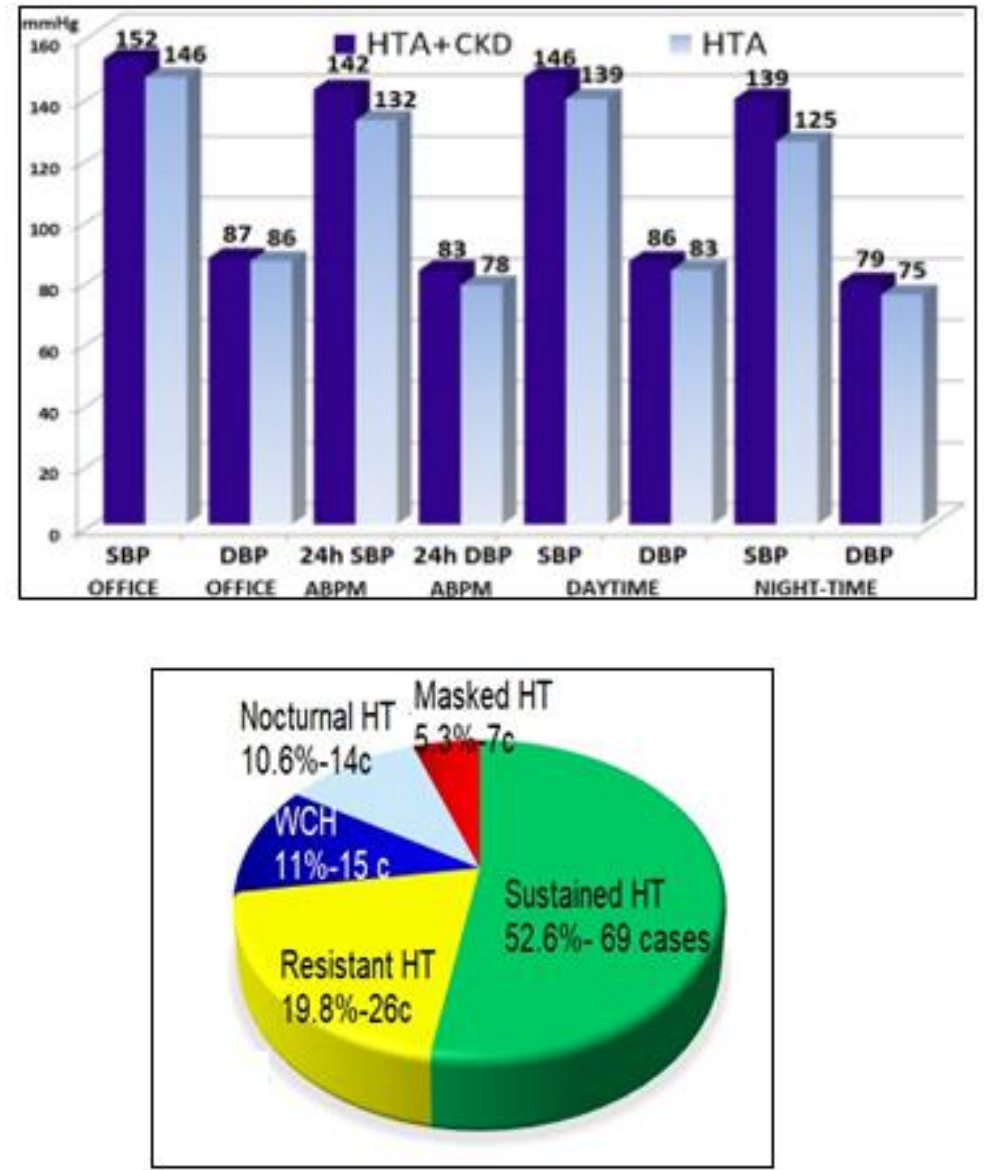

Figure 1. Office and ABPM systolic and diastolic BP in hypertension with and without CKD 
According to the office BP values, the control rate in hypertensive patients with CKD at the second visit was $24 \%$ (with BP targets of $<140 / 90 \mathrm{~mm} \mathrm{Hg}$ ) and $35 \%$ at the third visit. The control rate with 24 $\mathrm{h}$ ABPM was better than with office BP measurements. The night-time BP control was worse in hypertensive patients with CKD compared with hypertension without CKD $(21.77 \%$ vs. 32.03\%), $\mathrm{p}>0.05$.

"White-coat" hypertension (WCHT) was detected in 14 cases with CKD and in 15 cases without CKD. WCHT presented an appropriate prevalence in both hypertensive groups, with and without CKD (10.69\% vs $10.57 \%)$. Mean office BP were higher in WCHT with CKD, compared with WCHT without CKD, both for SBP $(155 \pm 8.00 \mathrm{~mm} \mathrm{Hg}$ vs.150.77 $\pm 5.27 \mathrm{~mm} \mathrm{Hg}, \mathrm{p}<0.05)$ and for DBP $(95.52$ $\pm 4.95 \mathrm{~mm} \mathrm{Hg}$ vs. $92.55 \pm 5.27 \mathrm{~mm} \mathrm{Hg}$ ), as presented in Table 2. Exemplifications of ABPM representations of BP in hypertensive patients with CKD are presented in Figures 3-4.

Table 2. Office blood pressure and ABPM measurements in "white-coat" hypertension

\begin{tabular}{|c|c|c|c|}
\hline BP values in WCHT & WCHT with CKD & WCHT without CKD & $\boldsymbol{p}$ value \\
\hline Office SBP & $155 \pm 8.00$ & $150.77 \pm 5.27$ & $<0.05$ \\
\hline Office DBP & $95.52 \pm 4.95$ & $92.55 \pm 3.83$ & $<0.05$ \\
\hline Daytime SBP & $129.88 \pm 3.62$ & $127.77 \pm 3.97$ & $<0.05$ \\
\hline Daytime DBP & $79.82 \pm 3.5$ & $78.88 \pm 4.02$ & $<0.05$ \\
\hline Night-time SBP & $115.64 \pm 2.80$ & $111 \pm 5.39$ & $<0.01$ \\
\hline Night-time DBP & $62.76 \pm 2.25$ & $64.94 \pm 3.03$ & $<0.05$ \\
\hline 24h SBP & $122.76 \pm 2.82$ & $120.38 \pm 3.26$ & $<0.05$ \\
\hline 24h DBP & $72.29 \pm 2.41$ & $71.91 \pm 2.93$ & $<0.05$ \\
\hline Prevalence of WCHT & $10.69 \%$ & $10.57 \%$ & NS \\
\hline
\end{tabular}

Abbreviations: SBP, systolic blood pressure; DBP, diastolic blood pressure; WCHT, white coat hypertension.

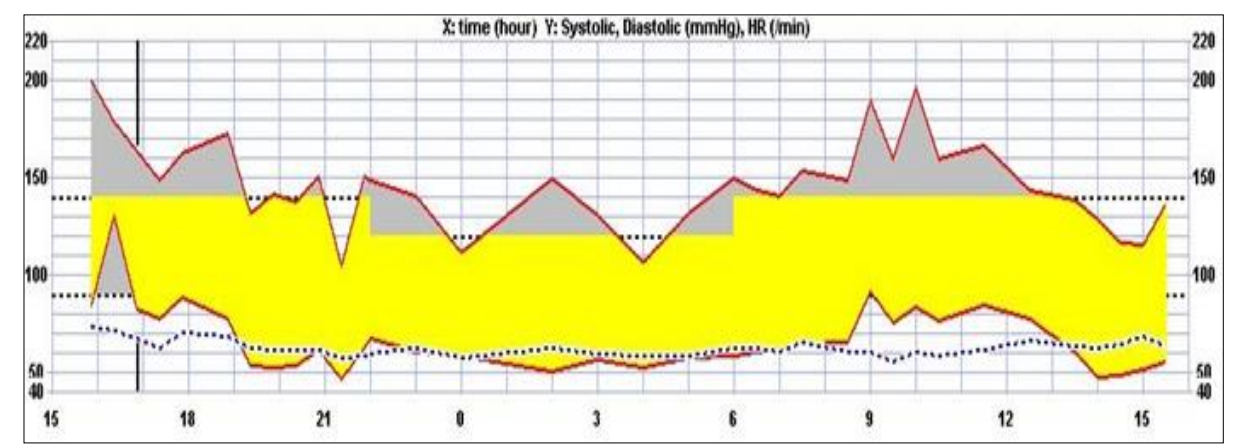

Figure 3. ABPM in systolic hypertension with CKD

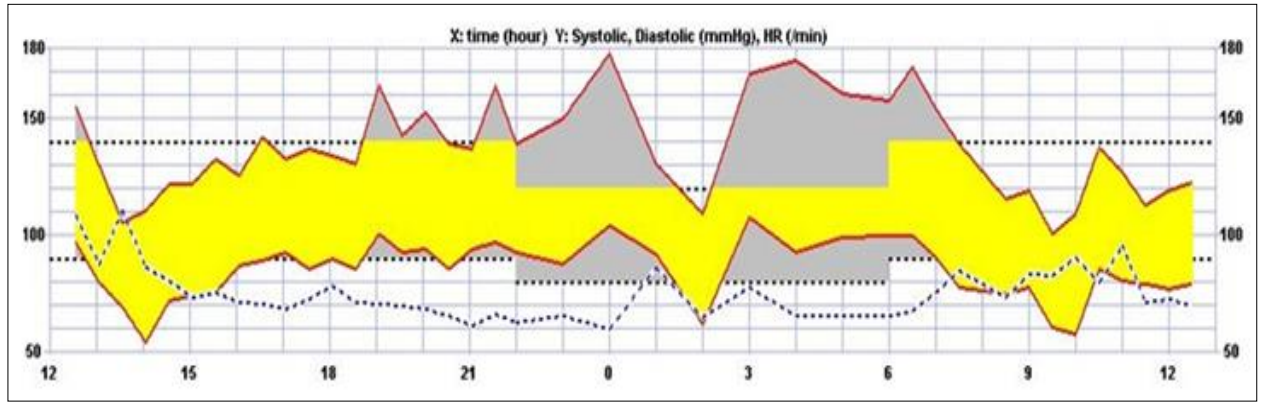

Figure 4. ABPM in nocturnal hypertension with CKD

The abnormal circadian BP pattern detected in CKD patients were the following: (1) reduced dipper pattern $(28.22 \%$ vs. $44.53 \%, \mathrm{p}<0.001)$; (2) high non-dipper pattern $(47.58 \%$ vs. $39.06 \%), \mathrm{p}$ $<0.05$; (3) high riser pattern (19.37\% vs. $9.38 \%)$, p<0.001 and (4) reduced extreme dipper (4.83\% vs. $7.03 \%) \mathrm{p}<0.001$, as presented in Figures 5 and 6. 

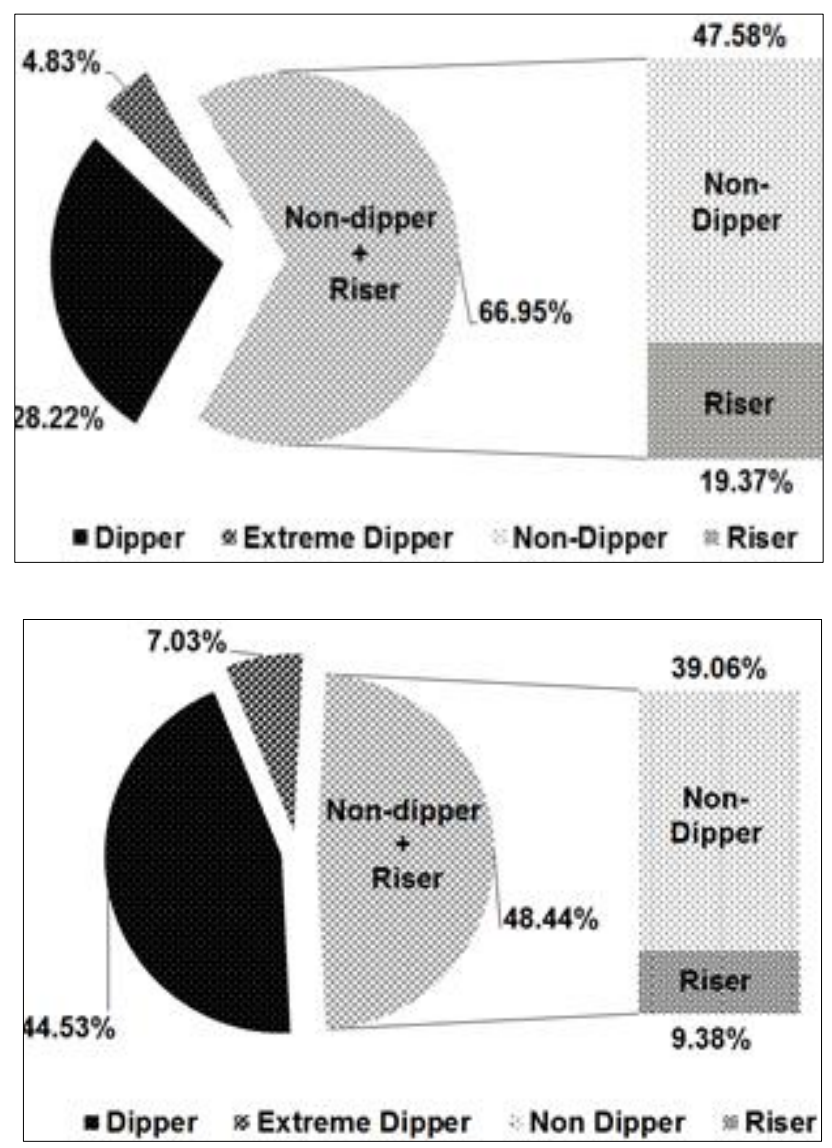

Figure 5. Circadian BP pattern in hypertensive patients with chronic kidney disease
Figure 6. Circadian BP pattern in hypertensive patients without chronic kidney disease

The hypertension group with CKD included more non-dippers (47.5\% vs 39.06\%), the greatest differences between groups were concerning a double higher incidence of the riser pattern $(19.35 \%$ in CKD group vs. $9.38 \%$ in hypertension without CKD), $\mathrm{p}<0.05$. Hypertensive patients with CKD presented the worst circadian BP pattern, as the prevalence of non-dipper and riser pattern was great, respectively $66.95 \%$, compared with $48.44 \%$ in the hypertension group without CKD. The ABPM study detected in hypertensive subjects with CKD a great prevalence of high systolic BP and alterations of the circadian BP, which are linked in the literature with the very high CV risk of hypertension with CKD.

The dysregulation of the lipid metabolism met in hypertensive patients with CKD contributes to the pathogenesis of cardiovascular disease and adverse consequences of the CKD population. In the study, serum total cholesterol, triglycerides and LDL cholesterol concentrations were significantly higher in hypertensive patients with CKD and HDL-cholesterol levels lower, than in hypertensive without CKD.

Comparison of hypertensive with CKD versus hypertensive without CKD revealed the following lipid profile data: high LDL-cholesterol in 52\% vs $45.5 \%$, high triglycerides in $50.3 \%$ vs $31.6 \%$ and low HDL cholesterol in 35.8\% vs 30\%, p<0.05 for all comparisons, as presented in Figure 7.

In the hypertensive patients with CKD the total cholesterol significantly increased with age, overweight and more in males than females. TG were slightly more elevated in males than females. There was a significant association between low serum HDL cholesterol, elevated triglycerides and obesity in hypertension with CKD.

In the hypertension group with CKD, compared with hypertension without CKD, mean LDL cholesterol values and that of triglycerides were higher and HDL cholesterol was lower, the differences being statistically significant, as presented in Table 3. 

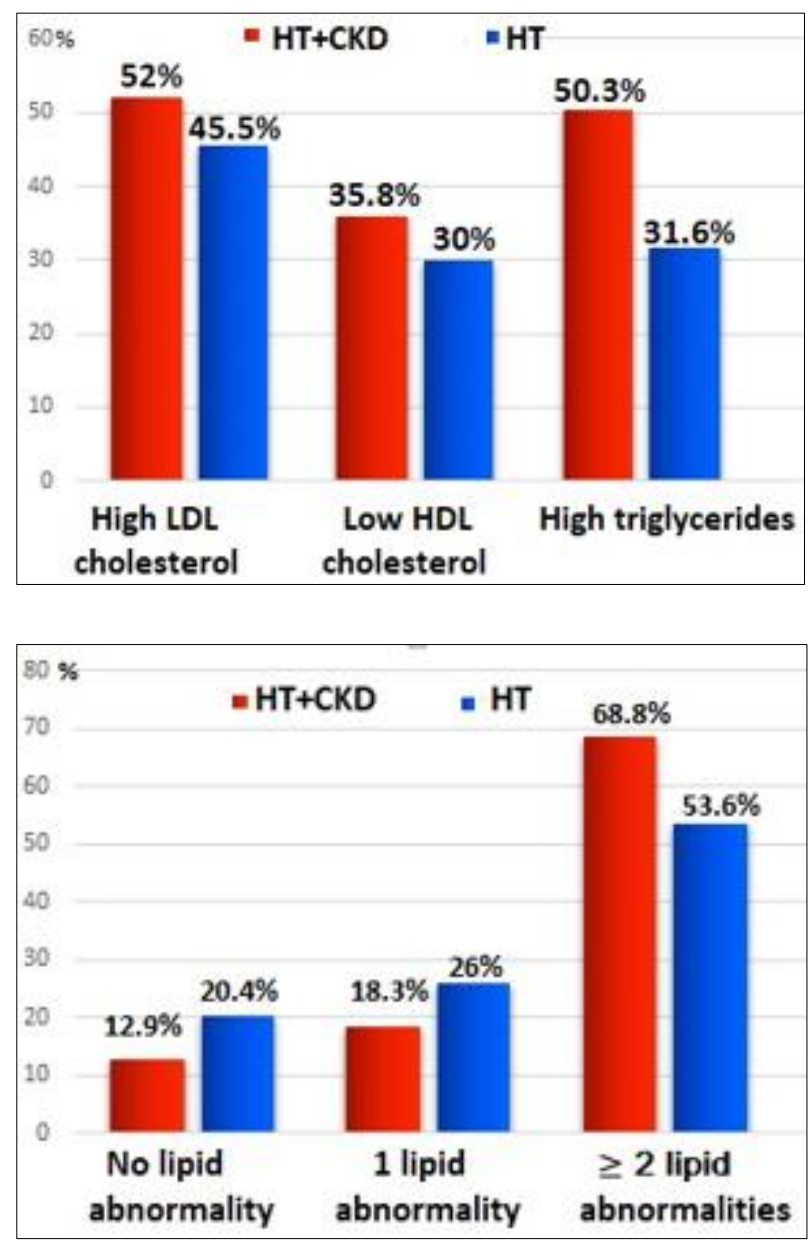

Figure 7. Lipid profile in hypertension with and without CKD
Figure 8. Number of lipid abnormalities in hypertension with and without CKD

Table 3. Lipid values in hypertension without and with CKD

\begin{tabular}{|c|c|c|c|}
\hline & $\begin{array}{c}\text { Hypertension } \\
\text { Vathout CKD }(\mathrm{nr}=142)\end{array}$ & $\begin{array}{c}\text { Hypertension } \\
\text { with CKD }(\mathrm{nr}=131)\end{array}$ & $\mathrm{p}$ \\
\hline Total cholesterol & $225 \pm 53$ & $235 \pm 55$ & 0.04 \\
\hline LDL cholesterol, mean $\pm \mathrm{SD}, \mathrm{mg} / \mathrm{dL}$ & $124 \pm 33$ & $129 \pm 35$ & 0.04 \\
\hline HDL cholesterol, mean $\pm \mathrm{SD}, \mathrm{mg} / \mathrm{dL}$ & $46 \pm 17$ & $40 \pm 18 \mathrm{mg} / \mathrm{dL}$ & 0.04 \\
\hline Triglycerides, $\mathrm{mg} / \mathrm{dL}$ & $129 \pm 95$ & $141 \pm 98.8$ & 0.03 \\
\hline $\mathrm{eGFR}, \mathrm{ml} / \mathrm{min} / 1.73 \mathrm{~m}^{2}$ & $70 \pm 8$ & $58 \pm 12$ & 0.01 \\
\hline $\mathrm{ACR}, \mathrm{mg} / \mathrm{g}$ & $14 \pm 6$ & $138 \pm 24$ & 0.001 \\
\hline
\end{tabular}

Abbreviations: eGFR, estimated glomerular filtration rate; ACR, albumin to creatinine ratio

Regarding the prevalence of various serum lipid abnormalities in hypertension with CKD compared with hypertension without CKD, no lipid abnormalities were met in 17 cases (12.9\%) vs 29 cases $(20.4 \%)$. One lipid disorder was present in 24 cases $(18.3 \%)$ of CKD patients' vs 37 cases $(26 \%)$ in hypertension without CKD and $\geq 2$ lipid disorders were present in 90 patients with CKD $(68.8 \%)$ vs 76 cases $(53.6 \%)$ in hypertension without CKD, as presented in Figure 8. The coexistence of hypertension and dyslipidemia was more frequently met in hypertension with CKD, presenting multidimensional clinical implications. The combination enhanced the cardiovascular risk, being also associated to obesity and consequent insulin resistance, which play major roles in the pathogenesis of both hypertension and dyslipidemia.

In our study, hypertensive patients with CKD, compared with hypertensive subjects without CKD, presented higher office SBP and ambulatory SBP during day and night-time and a lack of BP control, especially during the night-time [10-11]. Analysis of the circadian pattern in hypertension with CKD, compared to hypertension without $\mathrm{CKD}$, indicated the prevalence of an unfavourable non-dipping pattern in $66.9 \%$. Studies have demonstrated that the inadequate BP control in these patients is 
associated with a greater incidence of target organ damage and of cardiovascular diseases [12-14]. Similar data concerning the circadian pattern were found by Gorostidi et al. on the database of the Spanish Hypertension ABPM Registry $[2,14]$. The high prevalence of a non-dipper pattern was also influenced by the presence of diabetes, advanced age and association of other risk factors as dyslipidaemia. The elevated BP levels and the absence of the physiological nocturnal BP dipping has high predictive values for organ damage and worse prognosis [15]. Many trials confirm the observation that the control rate of hypertensive patients with CKD is worst during night and better during daytime [16-17]. Uncontrolled night-time hypertension can partially be explained by vascular hypertrophy and atherosclerosis secondary to hypertension, and by the fact that some administrated drugs do not assure a complete 24-h coverage. A blunted night-time BP decline may also reflect an autonomic dysfunction. It is considered that nocturnal hypertension represents an increased risk for cardiovascular mortality [18]. Another pathophysiological mechanism that is involved in nocturnal hypertension is obstructive sleep apnoea, frequently encountered in hypertension with CKD. Studies have demonstrated that nocturnal hypertension should be suspected in subjects with obstructive sleep apnoea, with autonomic dysfunction and organ damage, especially when the renal system is affected. An unfavourable control rate of hypertension was observed in CKD hypertensive patients, in spite of the fact that they received more antihypertensive drugs, data confirmed also by other studies [19].

Abnormalities in serum lipid and lipoprotein levels are recognized as major modifiable CVD risk factors. Dyslipidemia is more common in hypertensive than normotensive subjects, lipid levels increasing parallel with BP increase [20]. Many studies have shown that total cholesterol (TC), triglycerides, HDL cholesterol and virtually all fractions of lipoproteins tend to be abnormal among hypertensive patients, especially when CKD is associated [21].

Multiple metabolic abnormalities often accompany primary hypertension with CKD [22, 23]. Decreased HDL cholesterol, together with increased plasma levels of LDL cholesterol and VLDL, hypertriglyceridemia and insulin resistance are characteristic for hypertension with CKD. High levels of serum cholesterol are known to increase the risk of vascular complications such as coronary heart disease and stroke, characteristic for CKD. Many epidemiological studies indicated the increase in coronary heart disease risk when the serum TC exceeds $5.0 \mathrm{mmol} / \mathrm{L}$ [24-25], which prompted studies to suggest that levels of serum TC in the range 5.0-6.5 $\mathrm{mmol} / \mathrm{L}$ are to be considered undesirable. There was a positive and significant correlation between serum cholesterol and systolic and diastolic BP in both hypertensive patients, with and without CKD. Treatment of hypertension must be associated with correction of dyslipidemia to targets [25-26]. Low HDL-C was a common lipid abnormality among the study participants. The ATP III guidelines consider isolated HDL cholesterol a distinct form of atherogenic dyslipidemia, which can produce endothelial damage and the increase in blood pressure, being a powerful predictor of high and very high cardiovascular risk and aggravating CKD [26]. Studies have shown that a decrease in HDL-cholesterol of $1 \mathrm{mg} / \mathrm{dL}$ is associated with a $2 \%$ increase in the risk of coronary heart disease in men and 3\% increase in women [27-29].

Limitations of the study are the relatively small sample size of hypertension with CKD, the selection criteria based on visits at the GPs, which could introduce bias and the reliance upon a single 24-h ABPM evaluation per subject. Due to the cross-sectional design of the study, there were no follow up data regarding the evolution and prognosis of the hypertensive patients with CKD.

\section{Conclusions}

Hypertensive patients with CKD, compared with those without CKD, had an older age, longer duration of hypertension, more associated risk factors and cardiovascular diseases. The study showed that lipid abnormalities are highly prevalent among hypertensive patients with CKD. Elevated levels of cholesterol, LDL, VLDL, triglycerides and low LDL cholesterol were observed, compared with hypertensive without CKD. An altered circadian BP pattern was more frequently met in CKD hypertensive patients, with the prevalence of nocturnal riser and non-dipper pattern. On ABPM they registred higher systolic and diastolic BP, the systolic BP, both for $24 \mathrm{~h} \mathrm{SBP}$, day-time and night-time 
SBP being statistical significantly higher than in hypertesnive without CKD. Efforts should be made for fully evaluation in primary care of hypertensive with CKD from the lipid standpoint. Treatment of BP to targets and of detected lipid abnormalities is strongly recommended in this group of very highrisk patients.

\section{References}

1.WILLIAMS, B., MANCIA, G., SPIERING, W., AGABITI ROSEI, E., AZIZI, M., BURNIER, M., CLEMENT, D.L., COCA, A., DE SIMONE, G., DOMINICZAK, A., KAHAN, T., MAHFOUD, F., REDON, J., RUILOPE, L., ZANCHETTI, A., KERINS, M., KJELDSEN, S.E., KREUTZ, R., LAURENT, S., LIP, G.Y.H., MCMANUS, R., NARKIEWICZ, K, RUSCHITZKA, F., SCHMIEDER, R.E., SHLYAKHTO, E., TSIOUFI, S.C., ABOYANS, V., DESORMAIS, I., 2018 ESC/ESH Guidelines for the management of arterial hypertension. The Task Force for the management of arterial hypertension of the European Society of Cardiology (ESC) and the European Society of Hypertension (ESH), Eur Heart J, 39, 2018, 3021-3104.

2.GOROSTIDI, M., SOBRINO, J., SEGURA, J., SIERRA, C., DE LA SIERRA, A., HERNÁNDEZ DEL REY, R., VINYOLES, E., GALCERAN, J.M., LOPEZ-EADY. M.D., BANEGAS, J.R., COCA, A., RUILOPE LM., Ambulatory blood pressure monitoring in hypertensive patients with high cardiovascular risk: a cross-sectional analysis of a 20000-patient database in Spain. J Hypertens, 25(4), 2007, 977-984.

3.LEVIN, A., STEVENS, P.E., Summary of KDIGO 2012 CKD Guideline: behind the scenes, need for guidance and a framework for moving forward. Kidney int. 85(1), 2014, 49-61

4.DOROBANTU, M., TAUTU, O.F., DIMULESCU, D., SINESCU, C., GUSBETH-TATOMIR, P., ARSENESCU-GEORGESCU C, MITU F, LIGHEZAN D, POP C, BABES K, GIUCA A, BRANZA I, UDRESCU, M., HERDEA, V., DARABONT, R., Perspectives on hypertension's prevalence, treatment and control in a high cardiovascular risk East European country: data from the SEPHAR III survey, J Hypertens, 36(3), 2018, 690 -700.

5.DOROBANŢU, M., DARABONT, R., GHIORGHE, S., ARSENESCU-GEORGESCU, C., MACARIE, C., MITU, F., LIGHEZAN, D., MUSETESCU, R., POP, C., ARDELEANU, E., CRAIU, E., TĂUTU, O.F., Hypertension prevalence and control in Romania at a seven-year interval. Comparison of SEPHAR I and II surveys, J Hypertens, 32(1), 2014, 39-47.

6.GAMAN, M.A., DOBRICA, E.C., PASCU, E.G., COZMA, M.A., EPINGEAC, M.E., GAMAN, A.M., PANTEA STOIAN, A.M., BRATU, O.G., DIACONU, C.C. Cardio metabolic risk factors for atrial fibrillation in type 2 diabetes mellitus: Focus on hypertension, metabolic syndrome and obesity, $\mathrm{J}$ Mind Med Sci. 6(1), 2019, 157-161.

7.***Third Report of the National Cholesterol Education Program (NCEP), Expert panel on detection, evaluation, and treatment of high blood cholesterol in adults (Adult Treatment Panel III) final report, Circulation, 106, 2002, 3143-3421.

8.CHEN, F., YANG, W., WENG, J., JIA, W., JI, L., XIAO, J., SHAN, Z., LIU, J., TIAN, H., JI Q, ZHU, D., GE, J., LIN, L., CHEN, L., GUO, X., ZHAO, Z., LI, Q., ZHOU Z, SHAN G, LU J., Albuminuria: Prevalence, associated risk factors and relationship with cardiovascular disease, J Diabetes Investig, 5(4), 2014, 464-471.

9.BORGHI C., Interactions between hypercholesterolemia and hypertension: implications for therapy," Current Opinion in Nephrology and Hypertension, 11(5), 2002, 489-496.

10.ARDELEANU, E., DOROBANȚU, M., LIGHEZAN, D., DARABONT,, R., GURGUS, D., DELEANU, A., NICOLA, P., SCRIPCA, M., TĂUTU, O. Evaluation of resistant hypertension in primary care settings. J. Hypertension Research, 1(2), 2015, 53-59.

11.ABU-AWWAD A., FOLESCU R., POP D.L., MOTOC A., OPREA D.M., TUDORAN M., ZAMFIR C.L., FAUR C.I., VERMESAN D., DELEANU B.N., ANDOR BC, HARAGUS HG. Morphometric characteristics of fibrocartilaginous tissue in the herniated intervertebral disc. Rom $\mathrm{J}$ Morphol Embryol, 2019, 60(2), 629-634. 
12.MOISI, M.I., RUS, M., BUNGAU, S., ZAHA, C.D., UIVAROSAN, D., FRATILA, O., TIT, D.M., ENDRES, L., NISTOR-CSEPPENTO, D.C., POPESCU, M.I., Acute coronary syndromes in chronic kidney disease: clinical and therapeutic characteristics, Medicina, 56, 2020, 118. doi:10.3390/ medicina56030118

13.GURGUS, D., ARDELEANU, E., GADAU, C., FOLESCU, R., TILEA, I., VARGA, A., ZAMFIR, A., BAAJ, T., Prevalence, Biochemical and Clinical Characteristics of Resistant Hypertension, Rev. Chim., 69(10), 2018, 2845-49.

14.CERASOlA, G., MULE, G., COTTONE, S., NARDI, E., CUSIMANO, P., Hypertension, microalbuminuria and renal dysfunction: the Renal Dysfunction in Hypertension (REDHY) study, J Nephrol, 21, 2008, 368-373.

15.GADAU, C., ARDELEANU, E., FOLESCU, R., TILEA, I., VARGA, A., ZAMFIR, A., BAAJ, T., BOANCA, A., Prevalence, Characteristics and Predictive Factors of Microalbuminuria in Resistant Systemic Arterial Hypertension, Rev. Chim., 69(9), 2018, 2425-2429

16.MATSUSHITA, K., VAN DER VELDE, M., ASTOR, B.C., WOODWARD, M., DE JONG, P.E., Association of estimated glomerular filtration rate and albuminuria with all-cause and cardiovascular mortality in general population cohorts: a collaborative meta-analysis, Lancet, 375, 2010, 2073-2081.

17.AHMED, A. A., PREJBEANU, R., VERMESAN, D., DELEANU, B., IONITESCU, M., FLORESCU, S., VLAD, C.D., DUMITRASCU, V., Dose Effect of Local Betamethasone Injection in Low Back Pain, Rev. Chim., 69(9), 2018, 2382-2384.

18.LEVY, A., CORESH, J., Chronic Kidney Disease, Lancet, 379, 2012, 165-180.

19.SEGURA, J., CAMPO, C., GIL, P., ROLDAN, C., VIRGIL, L., RODICIO, J., RIULOPE, L., Development of Chronic Kidney Disease and Cardiovascular Prognosis in Essential Hypertensive Patients, J. Am. Nephrol, 15(2), 2004, 1616-1622.

20.PIEPOLI, M.F., HOES, A.W., AGEWALl, S., AlBUS, C., BROTONS, C., CATAPANO, A.L., COONEY, M.T., CORRA, U., COSYNS, B., DEATON, C., GRAHAM, I., HALL, M.S., HOBBS, F.D.R., LOCHEN, M.L., LÖLLGEN, H., MARQUES-VIDAL, P., PERK, J., PRESCOTT, E., REDON, J., RICHTER, D.J., SATTAR, N., SMULDERS Y, TIBERI M, VAN DER WORP HB, VAN DIS I, VERSCHUREN, W., BINNO, S., 2016 European Guidelines on cardiovascular disease prevention in clinical practice. Eur. Heart J, 37, 2016, 2315-2381.

21.LAAKSONEN, D.E., NISKANEN, L., NYYSS“ONEN, KT. A. LAKKA, J. LAUKKANEN A., SALONEN, T., Dyslipidemia as a predictor of hypertension in middle-aged men, E H. Journal, 29(20), 2008, 2561-2568.

22.ARDELEANU, E., DOROBANȚU, M., DARABONȚ, R., LIGHEZAN, D., LIGHEZAN, R., PURCĂRIŢĂ, D., DELEANU, A., GURGUS, D., NICOLA, P., BAAJ, S., Prevalence of microalbuminuria in hypertension monitored in primary care, Practica Medicala, 10(1), 2015, 50-55.

23.NICOLA, P., ARDELEANU, E., GADAU, C., DOROBANTU, M., DARABONT, R., TILEA, I., VARGA, A., BAAJ, T., Evaluation of Biochemical and Clinical Parameters of Hypertension with Type 2 Diabetes Mellitus, Rev. Chim., 69(9), 2018, 2402-2406.

24.AHMED, A.A., PREJBEANU, R., VERMESAN, D., BRANEA, I., DELEANU, B., FLORESCU, S., VLAD-DALIBORCA, C., Blood Loss of Pedicle Subtraction Osteotomy for Sagittal Imbalance Spinal Deformity, Rev. Chim., 69(12), 2018, 3680-3682

25.HORODINSCHI, R.N., STANESCU, A.M.A., BRATU, O.G., PANTEA STOIAN, A., RADAVOI, D.G., DIACONU, C.C., Treatment with statins in elderly patients, Medicina. 55(11), 2019, 721; doi: 10.3390 /medicina 55110721 .

26.TILEA, I., PETRA, D., VOIDAZAN, S., ARDELEANU, E., VARGA, A., Treatment adherence among adult hypertensive patients: a cross-sectional retrospective study in primary care in Romania. Patient Preference and Adherence, 12, 2018, 625-635.

27.MISCHIANU, D., CUMPANAS, A., PRECOP, C., BRATU, O., Urological emergencies, 2016, Academical Publishing Bucharest. 
28.FOLEY, R., WANG, C., COLLINS, A., Cardiovascular Risk Factor Profiles and Kidney Function Stage in the US General Population: The NHANES III Study, Mayo Clinic Proceedings, 80(10), 2012, 1270-1277.

29.GUCHI, K., HOSHIDE, S., ISHIKAWA, J., ISHIKAWA, S., PICKERING, T.G., GERIN, W., OGEDEGBE, G., SCHWARTZ, J.E., SHIMADA, K., KARIO, K., Cardiovascular prognosis of sustained and white-coat hypertension in patients with type 2 diabetes mellitus. Blood Press Monit 13(2), 2008, 15-20.

Manuscript received:3.06.2020 